\title{
Partial Uterine rupture in a primigravid patient, an uncommon obstetrical event: A Case Report.
}

\footnotetext{
1. MBBS, FCPS

Consultant Gynaecologist

Chiniot Mother and Child Hospital

Karachi.
}

Correspondence Address:

Dr. Kouser Karim Ladhani

Consultant Gynaecologist

Chiniot Mother and Child Hospital

Karachi.

dr.kouser@outlook.com

Article received on:

06/11/2020

Accepted for publication:

$18 / 11 / 2020$

\section{Kouser Karim Ladhani}

ABSTRACT... Rupture of the unscarred uterus in a primigravid patient is a very unusual event associated with high perinatal and maternal morbidity and mortality. Case Presentation: A 24-year-old primigravid woman, presented at term gestation with mild labor pains. During labor course there was pathological cardiotocography. An emergency cesarean was performed and a partial uterine rupture was found. Conclusion: Though a rare event but even in a primigravid patient, rupture of the uterus should be considered in pregnant women with hemoperitoneum, even when caesarean section is absent from the obstetric history.

Key words: $\quad$ Hemoperitoneum, Morbidity, Primigravid Patient.

Article Citation: Ladhani KK. Partial Uterine rupture in a primigravid patient, an uncommon obstetrical event: A case report. Professional Med J 2021; 28(4):610-613. https://doi.org/10.29309/TPMJ/2021.28.04.6198

\section{INTRODUCTION}

Uterine rupture is a very rare and unusual event during pregnancy and labour, especially in unscarred primi gravid patients. The overall incidence of uterine rupture in women with previous cesarean scar is around $1 \%$. It is a life threatening condition with significant maternal and fetal morbidity and mortality if not managed timely and properly. We report a case of partial uterine rupture of posterior wall in a primigravida during latent phase of labor, a very rare event.

\section{Case Presentation}

A 24 years old primigravida was admitted at term gestation with mild labor pains. On admission her cardiotograph was reactive. Contractions were mild and she was in latent phase of labor.

During her antenatal course, medical history was complicated by history of fall with syncope but no evidence of unconsciousness or history of fits or epilepsy. Her neurological evaluation was done, her workup was normal and she was prescribed alprazolam. She had no medical co morbid and her antenatal investigations including serum electrolytes, urea, creatinine. Liver function tests all were normal. Her blood pressures remained normal throughout. No history of addiction, any connective tissue disorder and uterine surgery or instrumentation in the past.

As far as her intrapartum course is concerned, she was left for spontaneous progress in labor. After 6hrs she had same vaginal findings with mild irregular pains so she was augmented with prostin E2 in posterior fornix of vagina after repeat reactive cardiotocograph. Her vitals and fetal heart remained normal. After 6 hours of prostaglandin E2 insertion, she had two episodes of vomiting with complain of abdominal pain. Her blood pressure was $100 / 60 \mathrm{~mm} / \mathrm{Hg}$, pulse $105 /$ minute and cardiotocography showed pathological trace with prolonged decelerations. On vaginal examination cervical os was $3 \mathrm{~cm}$ dilated with membranes intact and no per vaginal bleeding.

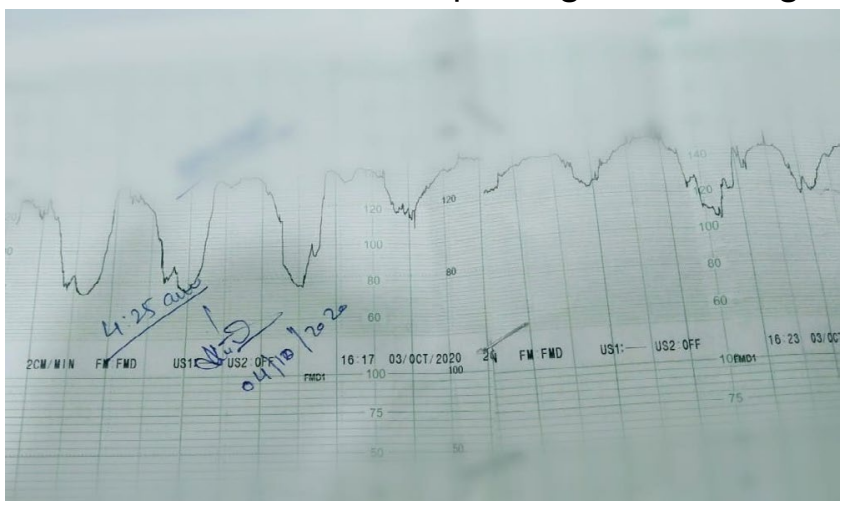


So decision for emergency cesarean delivery was made. On opening abdominal cavity, there was hemoperitoneum of about $1000 \mathrm{ml}$. Anterior uterine wall was found intact. Baby delivered. Liqour was clear and Apgar score of baby was $6 / 1,8 / 5$. Placenta was normal no evidence of abruption. Inner uterine cavity was found to be intact on examination. On posteriolateral uterine wall of uterus there was huge organized hematoma extending from uterine fundus till cervix with mild oozing but no active bleeding. Abdominal cavity explored no other evidence of bleeding. There was no active bleeding so surgicell (haemostatic agent) was placed over hematoma/partial incomplete rupture site. Hysterectomy was not done. Abominal drain inserted, uterine incision closed back. Good hemostasis secured and abdominal cavity closed. Estimated blood loss was 2 liter. No blood products were administered intraoperatively.

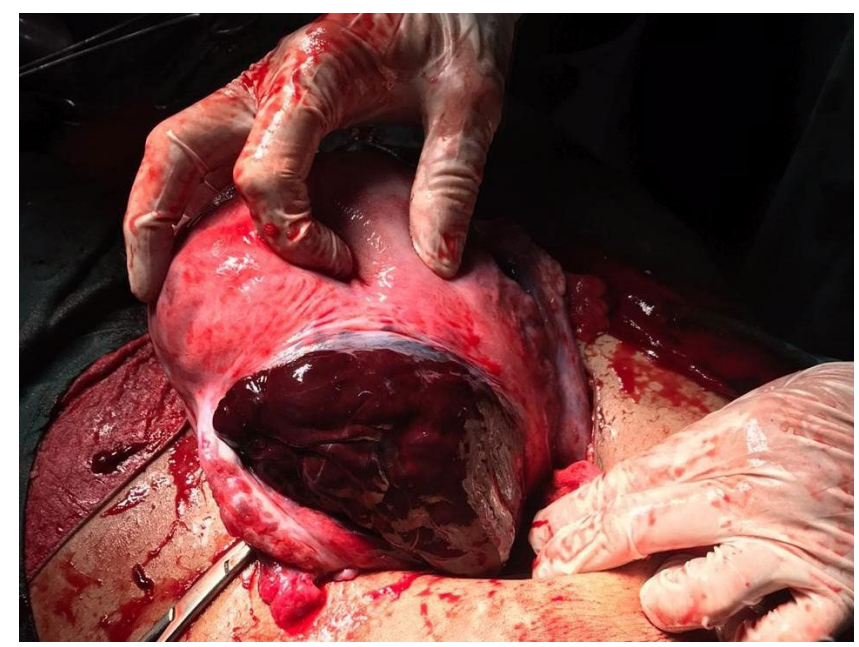

Patient was shifted to high dependency unit; vitals were Blood pressure $100 / 60 \mathrm{~mm} / \mathrm{Hg}$, Pulse 120/min after fluid resuscitation. Because of risk of occult intra abdominal bleeding, she was monitored frequently. Her immediate post operative hemoglobin was $5.4 \mathrm{gm} / \mathrm{dl}$ which was dropped from $10.1 \mathrm{gm} / \mathrm{dl}$ on admission. She was transfused 5 pints pack cells, 6 pints FFPS. Her hemoglobin on 1st post operative day wa10.5gm/ dl which remained static on second and third postoperative day her tachycardia settled after transfusion. On drain output there was $30 \mathrm{cc}$ serosanguinous fluid on 1st postoperative day then drain output remained nil. Urine output was also remained adequate. Her ultrasound was done on $2^{\text {nd }}$ postoperative day, showed no intrabdominal collection or evidence of hematoma.

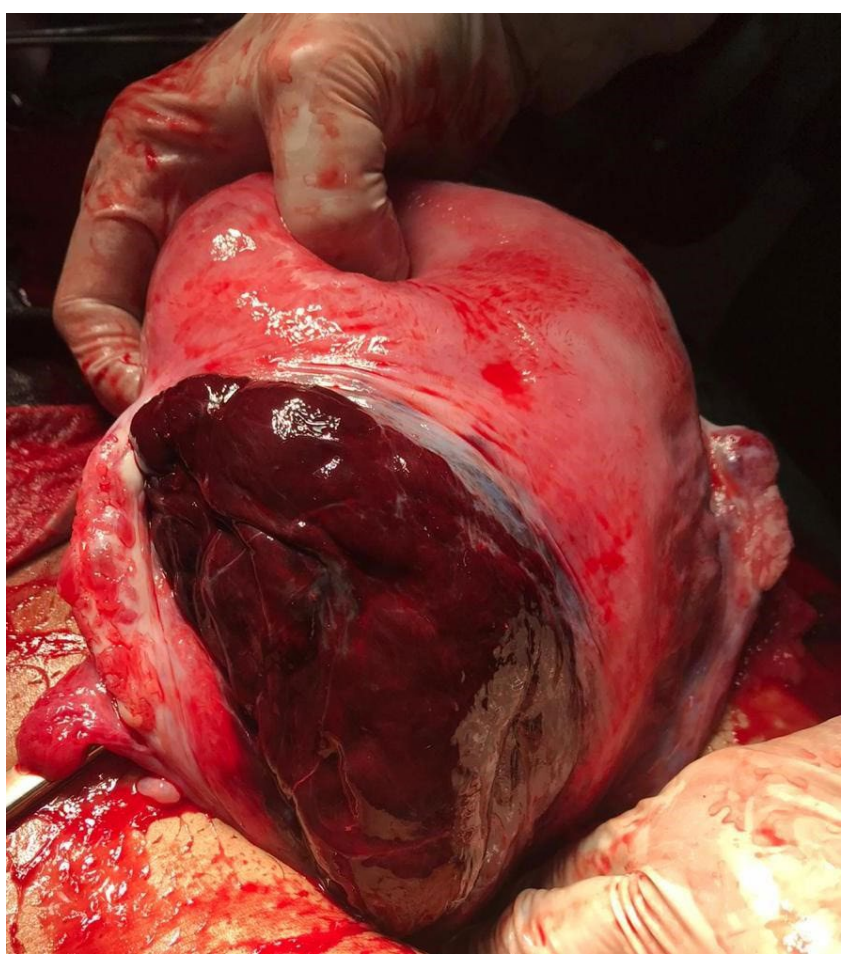

She was discharged on $5^{\text {th }}$ post operative day in a stable condition.

The neonate weight was $3000 \mathrm{gm}$ with Apgar scores of 4,6 and 8 at 1,5 and 10 minutes respectively.

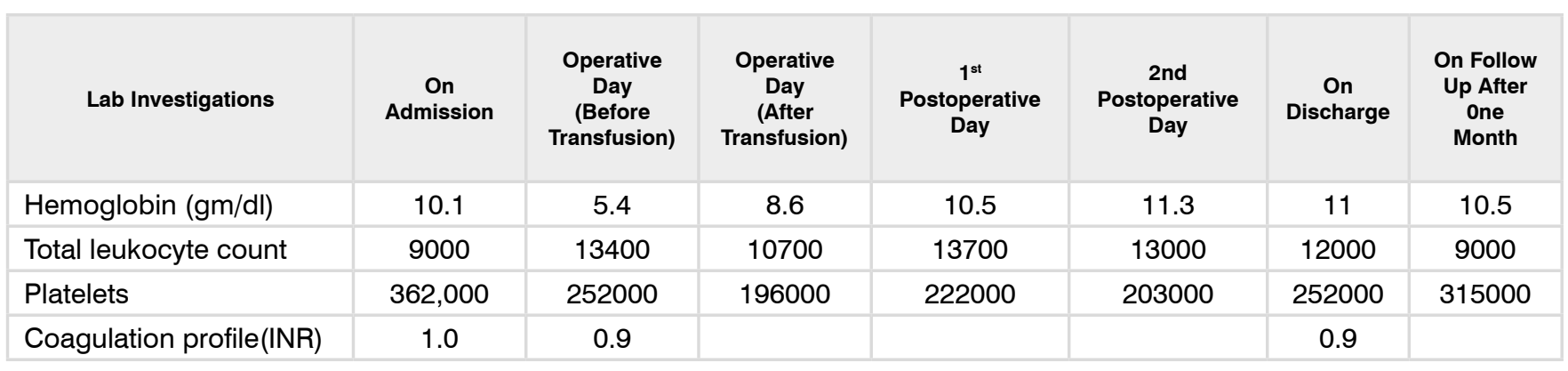


He required cardio pulmonary resuscitation but no intubation or mechanical ventilation. He was managed in NICU and survived a complicated neonatal course. He had jerky movement on second neonatal day but was managed with phenobarbitone. He was discharged on $5^{\text {th }}$ day of birth in a stable condition.

\section{Outcome \& Follow-Up}

Patient follow up on 12th postoperative day was stable, up and about, her stitch line was healthy.

She again followed up after 1 month, her ultrasound pelvis was insignificant and her hemoglobin was $10.5 \mathrm{gm} / \mathrm{dl}$.

\section{DISCUSSION}

Uterine rupture in non-scarred women especially in primigravida is a very rare and unusual event and can be life-threatening for both mother and fetus if not managed properly and timely. The prevalence of uterine rupture in pregnancy with history of previous cesarean section is around $1 \%^{1}$ and it accounts for about ninety percent of total cases occur in women with a previous scar. ${ }^{2,3}$ In women without a history of Caesarean section, the incidence of uterine rupture in developed countries is $0.006 \%$ based on a World Health Organization systematic review ${ }^{2}$ and it is around $1 / 920$ pregnancies $(0.11 \%)$ in developing countries. ${ }^{4}$

Previous case reports on uterine rupture on unscarred uterus showed that the most common rupture sites were the cornual area and the uterine fundus. ${ }^{5}$ In our case, during surgery the tear in our patient's uterus was on posteriolateral left wall of uterus. The pathogenesis of rupture of the unscarred uterus is not well known. Associated factors include trauma (domestic violence, traffic accident), obstetric maneuvers (internal version, breech extraction), Medical induction or augmentation (oxytocin stimulation), intrauterine surgery, multiparity, oxytocin stimulation, placenta acreta, Ehlers-Danlos syndrome, cocaine abuse, in-utero exposure to diethylstilbestrol, uterine anomalies, and obstructed labor. ${ }^{6}$ Almost all these factors were absent in our pt except that she was induced with prostaglandin E2 once.
Unusual presentation of uterine rupture is very common during pregnancy because of gravid uterus and difficulty in diagnosis. Same happened in our case. But adequate fluid replacement, optimal blood transfusion, and surgical intervention can significantly affect the prognosis. $^{7}$

Because of the rare incidence and the unusual presentation, rupture of the uterus in our case was not the primary diagnosis. In combination with abdominal pain and pathological cardiotocography, we decided for emergency caesarian because of fetal bradycardia. Rupture of the pregnant uterus is an uncommon but severe obstetrical event, which is associated with high perinatal and maternal morbidity and mortality. So rupture of the pregnant uterus should always be considered in a pregnant woman presenting with abdominal pain, even in a primigravid patient.

The underlying cause of Uterine rupture in our patient is not clear may be its related to trauma as she had history of fall in the past aur it can be attributed to collagen vascular disorder that was not proven.

\section{CONCLUSION}

Though uterine rupture is a rare event especially in unscarred uterus. It can be life threatening to both mother and baby because of unusual presentation and delayed diagnosis. So rupture of the uterus should be considered in pregnant women with hemoperitoneum, even when caesarean section is absent from the obstetric history. Although spontaneous rupture of the primigravid uterus is indeed a very rare event, a number of such cases have been reported in the past so. Prompt recognition and management of uterine rupture is critical in influencing perinatal and maternal morbidity.

\section{Copyright $@ 18$ Nov, 2020.}

\section{REFERENCES}

1. Kaczmarczyk M, Sparén $P$, Terry $P$, Cnattingius $S$. Risk factors for uterine rupture and neonatal consequences of uterine rupture: $A$ populationbased study of successive pregnancies in Sweden. BJOG 2007; 114:1208-14. 
2. Hofmeyr GJ, Say L, Gülmezoglu MM. WHO systematic review of maternal mortality and morbidity: The prevalence of uterine rupture. BJOG 2005; 112:12218.

3. Zwart JJ, Richters JM, Ory F, de Vries JIP, Bloemenkamp $\mathrm{KWM}$, van Roosmalen $\mathrm{J}$. Uterine rupture in the Netherlands: A nationwide population-based cohort study. BJOG 2009; 116(8):1069-80.

4. Nahum G. PK. Uterine rupture in pregnancy. Medscape 2012; 1-37.
5. Mizutamari E, Honda T, Ohba T, Katabuchi $H$. Spontaneous rupture of an unscarred gravid uterus in a primigravid woman at $\mathbf{3 2}$ weeks of gestation. Case Rep Obstet Gynecol. 2014; 2014:2095850.

6. Posthumus L, Donker ME. Uterine rupture in a primigravid patient, an uncommon but severe obstetrical event: A case report. Journal of Medical Case Reports (2017) 11:339.

7. Ripley DL. Uterine emergencies. Obstet Gynecol Clin North Am 1999; 26(3):419-34.

\section{AUTHORSHIP AND CONTRIBUTION DECLARATION}

\begin{tabular}{c|c|c|c|} 
Sr. \# & Author(s) Full Name & \multicolumn{1}{c|}{ Contribution to the paper } & Author(s) Signature \\
\hline 1 & Kouser Karim Ladhani & $\begin{array}{l}\text { Idea, Formulation, Paper } \\
\text { writing. }\end{array}$ & \\
\hline
\end{tabular}

